\title{
Rapid and Sensitive Speciation of Inorganic Iodine in Groundwater by IC-ICP-MS With Ar-CH 4 Mixed Plasma
}

\section{Wei Guo, Yanxin Wang, Junxia Li, Yue'e Peng, Lanlan Jin, Qinghai Guo, and Shenghong Hu* State Key Laboratory of Biogeology and Environmental Geology, China University of Geosciences, Wuhan, 430074, P. R. China}

\section{INTRODUCTION}

Iodine (I) is one of the most important trace elements in human nutrition, with its main physiological function as a constituent of thyroxine, the hormone secreted by the thyroid gland (1). Iodine deficiency can cause serious delays in neurologic development. However, excess iodine can also produce goiter, hypothyroidism, and hyperthyroidism (2). In some high-iodine areas (e.g., Datong basin, P.R. China), simultaneous consumption of high-iodine groundwater and iodized salt causes an iodine intake several times higher than regulatory levels, negatively affecting the thyroid gland (3). Since 2004, the Chinese government has adopted 150 and $300 \mu \mathrm{g} \mathrm{L}^{-1} \mathrm{I}$ as the amounts of iodine in groundwater to be the toxic exposure level and diseaseinducing concentration, respectively. Like other elements, iodine toxicity is species-dependent: iodate $\left(\mathrm{IO}_{3}{ }^{-}\right)$is less toxic than iodide $\left(\mathrm{I}^{-}\right)$and organically bound iodine (4). Hence, it is necessary to determine the iodine species in groundwater samples instead of total iodine.

Several liquid chromatography (LC), size-exclusion chromatography (SEC), capillary electrophoresis (CE), and ion chromatography (IC) methods coupled with different detection techniques for iodine or other element speciation have been reported. These include UV spectrophotometry, inductively coupled plasma optical emission spectrometry (ICP-OES), and inductively coupled plasma mass spectrometry

\footnotetext{
*Corresponding autbor.

E-mail: sbbu@cug.edu.cn
}

\section{ABSTRACT}

Investigation of the iodine species is important to better understand the sources and mobilization processes of highiodine groundwater. A fast and sensitive method for the determination of iodate $\left(\mathrm{IO}_{3}^{-}\right)$and iodide $\left(\mathrm{I}^{-}\right)$in groundwater using an improved ion chromatography method coupled with inductively coupled plasma mass spectrometry (IC-ICP-MS) is described. To shorten the separation time of iodine species, a short anion-exchange column, Dionex AG-19, was examined as the analytical column. Isocratic elution using $30 \mathrm{mM} \mathrm{KOH}$ facilitated the chromatographic separation of $\mathrm{IO}_{3}{ }^{-}$and $\mathrm{I}^{-}$within one minute, reducing the time in comparison to previous IC-ICPMS methods with conventional long IC columns (i.e., Hamilton $\mathrm{X}-100$ or Dionex AS-16) by $90 \%$. Moreover, the low analytical sensitivity of iodine, due to its high ionization potential (10.08 eV), was improved five-fold by addition of small amounts of $\mathrm{CH}_{4}$ to the Ar plasma. The detection limit was $0.005 \mu \mathrm{g} \mathrm{L}^{-1}$ for $\mathrm{IO}_{3}$ and $0.006 \mu \mathrm{g} \mathrm{L}^{-1}$ for $\mathrm{I}^{-}$, while the relative standard deviation for five injections of $0.2 \mu \mathrm{g} \mathrm{L}^{-1} \mathrm{I}^{-}$or $\mathrm{IO}_{3}{ }^{-}$was $1.2-3.3 \%$. The analytical results for three water standard reference materials were in agreement with the certified values. The proposed method was successfully applied to the determination of $\mathrm{I}^{-}$and $\mathrm{IO}_{3}{ }^{-}$in seven shallow groundwater samples collected from the Datong Basin, Northern China. The distributions of the iodine species, differing from mountain front plains to flat alluvial plain regions, indicate that the mobilization process of iodine is associated with complex redox conditions.
(ICP-MS) (5-11). Among these techniques, IC-ICP-MS could be a promising analytical technique for iodine speciation due to high sensitivity and element specificity of the ICP-MS detector (12-21). Recently, ICP-MS has been used for various environmental and biological samples for iodine speciation studies, including water, seaweeds, urine, human serum, and milk (4, 22-25). However, the low analytical sensitivity and lengthy processing times of previous IC-ICP-MS applications are major drawbacks. Generally, the total run time of one injection is between 10-20 minutes in ICICP-MS analysis with typical IC analytical columns, such as the Hamilton PRP-X100 and Dionex AG-16 (4, 26, 27). A long elution time not only affects the throughput, but also leads to errors in the results. This is due to the continuous introduction of a high salt mobile phase deposited onto the orifice of the MS interface, which influences the transmission of the target ions (28). Like other nonmetallic elements (e.g., As, Se, Hg), the iodine sensitivity in ICP-MS is only $10-30 \%$ that of most metal elements (e.g., Li, In, Pb) which could be due to its high ionization potential (10.08 eV) (29). Recently, it was confirmed that the addition of small amounts of carbon-containing compounds (e.g., methanol, glycerol) to the plasma could improve the signal intensities of As and Se up to 2-4 times (30-32). These experimental results indicate that the signal enhancement of elements with high ionization potentials $(9-11 \mathrm{eV})$ is mainly attributed to the increased degree of ionization in the plasma.

The aim of this study was to establish a rapid and sensitive 
IC-ICP-MS method for the determination of $\mathrm{IO}_{3}{ }^{-}$and $\mathrm{I}^{-}$in groundwater samples. A short anion-exchange chromatographic column was used instead of the usual long column to achieve the required high sample throughput, and the separation performance was carefully evaluated. In addition, a $\mathrm{CH}_{4}$-Ar mixed gas plasma was employed instead of conventional pure Ar-ICP to improve the sensitivity of I. Optimization of the proposed method, the influence of coexistent substances, the analytical feasibility of the technique, and its application to the determination of inorganic iodine species in seven groundwater samples are described.

\section{EXPERIMENTAL}

\section{Instrumentation}

The Dionex ${ }^{\mathrm{TM}}$ ICS900 IC separation system consists of an IC pump, an injection valve, column heater, and an AS-19 anion-exchange column (Thermo Fisher Scientific, USA). The samples were loaded into a $20-\mu \mathrm{L}$ sample loop with a syringe. The PerkinElmer NexION ${ }^{\circledR}$ 300D ICP-MS instrument was used (PerkinElmer, Inc., Shelton, CT, USA). The eluents were introduced into the ICP-MS with a pneumatic nebulizer and cyclonic spray chamber. The peak areas and peak heights were measured with Chromera ${ }^{\circledR}$ software (PerkinElmer, Inc.). The experimental setup is schematically represented in Figure 1. $\mathrm{CH}_{4}$ gas (99.999\%) was added into an additional port in the PC3 Peltier cyclonic spray chamber (Elemental Scientific, USA) via a calibrated mass-flow controller (Cole-Parmer, USA), capable of regulating minute flows (measuring range $0-1.0 \mathrm{~L}$ $\min ^{-1}$, precision $0.01 \mathrm{~L} \mathrm{~min}^{-1}$ ) of the gas. The IC-ICP-MS operating parameters are summarized in Table I.

Reagents, Standards, and Samples

High purity water $(\geq 18.2 \mathrm{M} \Omega$ $\mathrm{cm}^{-1}$ ) used for preparation of the blank, standards, and eluents was obtained from a Millipore ${ }^{\circledR}$ water purification system (Millipore Corporation, France). KI (99.9999\%), $\mathrm{KIO}_{3}(99.9999 \%)$, and $\mathrm{KOH}$ (99.9999\%) were purchased from Alfa Aesar Ltd. (Tianjing, P.R. China). Three standard reference materials (SRM) were used to assess method reliability. Groundwater SRM BCR-611 was purchased from the Institute for Reference Materials and Measurements (IRMM, European Commission). Two natural waters GBW 08621 and GBW (E) 080235 were purchased from the

TABLE I

IC-ICP-MS Operation Conditions

\begin{tabular}{|c|c|}
\hline IC System & Dionex $^{\mathrm{TM}}$ ICS900 \\
\hline Column & AS- 19 column $(50 \mathrm{~mm} \times 4 \mathrm{~mm}, 11 \mu \mathrm{m})$ \\
\hline Injection Volume & $10 \mu \mathrm{L}$ \\
\hline Flow Fate & $1 \mathrm{~mL} \mathrm{~min}^{-1}$ \\
\hline Column Temperature & $25^{\circ} \mathrm{C}$ \\
\hline Isocratic Elution & $30 \mathrm{mM} \mathrm{KOH}$ \\
\hline Run Time & $1 \mathrm{~min}$ \\
\hline ICP-MS System & PerkinElmer NexION® 300D ICP-MS \\
\hline Nebulizer & PFA MicroFlow Nebulizer \\
\hline Spray Chamber & Cyclonic (PC3 Peltier Chiller) \\
\hline Analytes & ${ }^{127} \mathrm{I}^{+}$ \\
\hline Plasma Gas Flow & $16 \mathrm{~mL} \mathrm{\operatorname {min } ^ { - 1 }}$ \\
\hline Auxiliary Gas Flow & $1.0 \mathrm{~mL} \mathrm{\operatorname {min } ^ { - 1 }}$ \\
\hline Nebulizer Gas Flow & $\begin{array}{l}0.85 \mathrm{~mL} \mathrm{~min} \mathrm{~min}^{-1}\left(\mathrm{CH}_{4} \text {-Ar mixed plasma }\right) \\
\left.0.92 \mathrm{~mL} \mathrm{~min} \text { min }^{-1} \text { (Ar plasma }\right)\end{array}$ \\
\hline Optional Gas $\left(\mathrm{CH}_{4}\right)$ & $3 \mathrm{~mL} \mathrm{~min}^{-1}$ \\
\hline RF Power & $1500 \mathrm{~W}$ \\
\hline Dwell Time & $100 \mathrm{~ms}$ \\
\hline
\end{tabular}

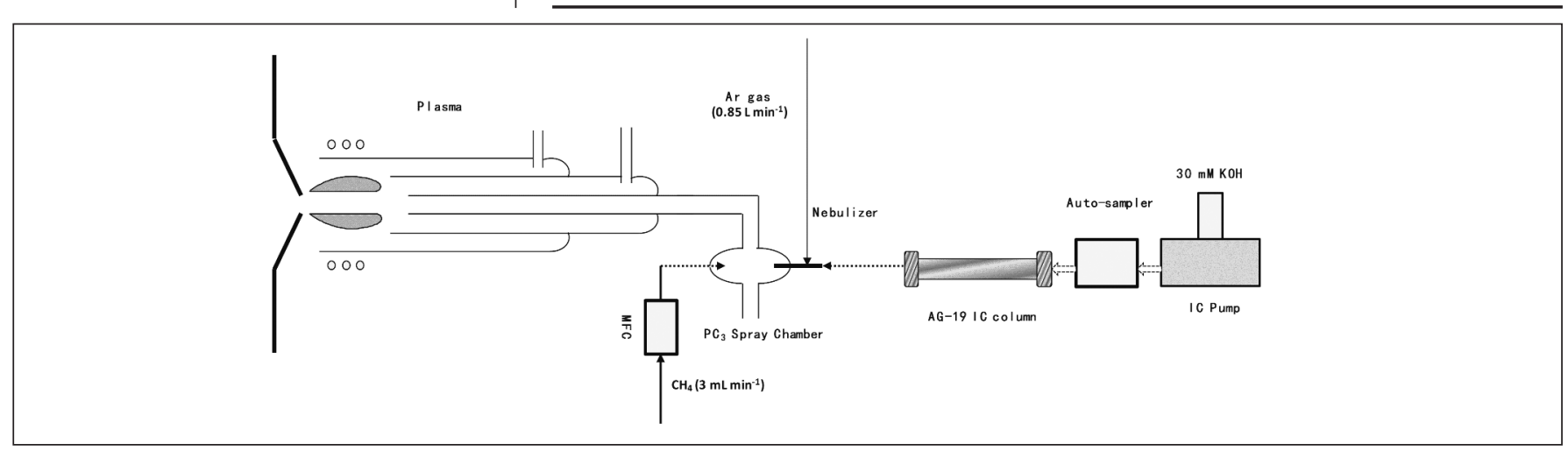

Fig. 1. Diagram of the experimental setup. 
National Research Center for Certified Reference Materials, P.R. China. Seven groundwater samples were collected from the Datong basin, Northwest China. All of the eluents and samples were filtered through a $0.45-\mu \mathrm{m}$ membrane filter (Macherey-Nagel, Germany) and subsequently degassed in an ultrasonic bath before analysis.

\section{RESULTS AND DISCUSSION}

\section{Reduction of Separation Times Using a Short Anion Exchange Column}

It is well known that IC has shown the most promise as a tool for separating different ions and the effluent can be directly introduced into a highly sensitive and selective ICP-MS via a conventional pneumatic nebulizer and spray chamber. A typical chromatogram of a solution containing $1 \mu \mathrm{g} \mathrm{L}^{-1}$ mixed standards of $\mathrm{IO}_{3}{ }^{-}$and $\mathrm{I}^{-}$by IC-ICP-MS with a conventional IC column (Dionex AS-19, $250 \mathrm{~mm} \times 4 \mathrm{~mm}$, $7.5 \mu \mathrm{m})$ is shown in Figure 2 (dashed line). Under optimal conditions (mobile phase: $30 \mathrm{mM} \mathrm{KOH}$, flow rate: $1 \mathrm{~mL} \mathrm{~min}^{-1}$ ), the retention times of $\mathrm{IO}_{3}{ }^{-}$and $\mathrm{I}^{-}$were 3.1 and 14.5 minutes, respectively. To reduce the total run time of one injection, a short IC column (Dionex AG-19, $50 \mathrm{~mm} \times 4 \mathrm{~mm}$, $11 \mu \mathrm{m})$ was used instead of a long column. As shown in Figure 2 (solid line), the retention times of $\mathrm{IO}_{3}{ }^{-}$and $\mathrm{I}^{-}$were reduced to 0.36 and 0.64 minutes, respectively, with narrower and taller peak profiles. The total run time for one injection was, therefore, less than one minute, allowing a theoretical sample throughput of up to 60 samples per hour.

\section{Signal Improvement by Addi- tion of $\mathrm{CH}_{4}$ to the Plasma}

In comparison with another mono-isotopic elements such as $\mathrm{Rh}$, the sensitivity of I is only one-tenth that of $\mathrm{Rh}$ because of the low ionization efficiency of I in the plasma. Some studies have reported that addition of $3-5 \%$ carbon-containing compounds could increase the signal intensity of high ionization energy elements in ICP-MS analysis (e.g., As, Se, and Hg) (29, 31-33). To improve the poor sensitivity of $\mathrm{I}$, a carbon source $\left(\mathrm{CH}_{4}\right.$ gas) was directly introduced into the plasma by an additional port in the cyclonic spray chamber. A lower nebulizer gas flow rate $\left(0.85 \mathrm{~mL} \mathrm{~min}^{-1}\right.$

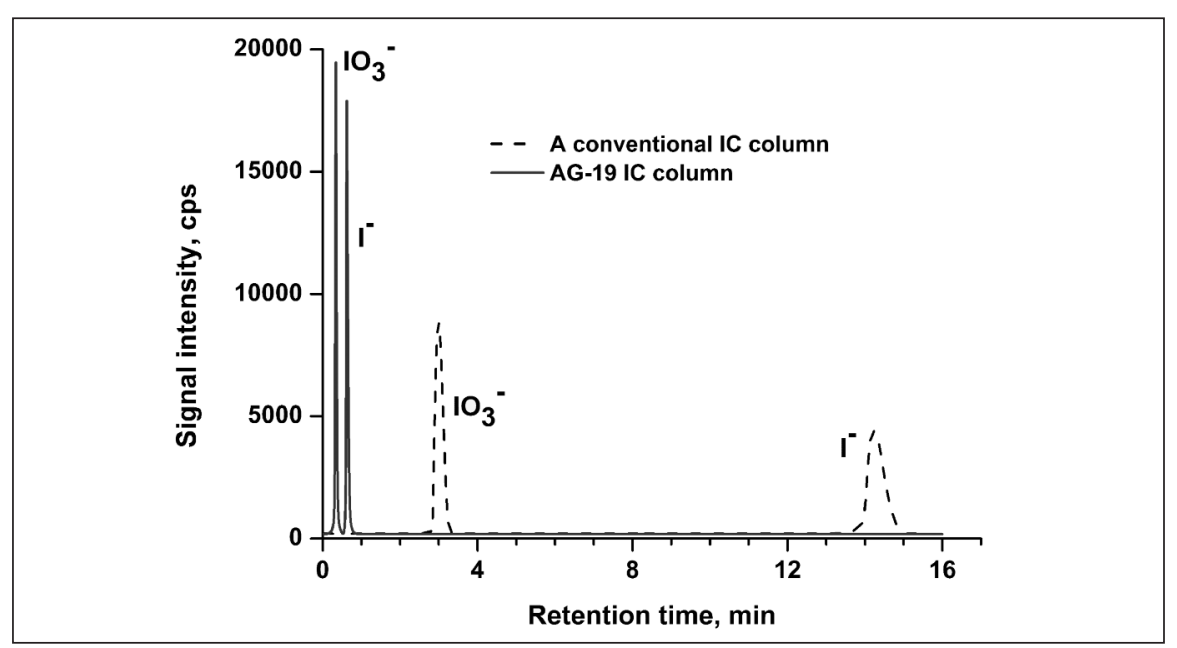

Fig. 2. Typical chromatograms for solution containing $1 \mu \mathrm{g} \mathrm{L}^{-1} \mathrm{IO}_{3}^{-}$and $1 \mu g \mathrm{~L}^{-1} \mathrm{I}^{-}$ acquired with IC-ICP-MS (at m/z 79) using a conventional Dionex AS-19 IC column (dashed line) and a short Dionex AS-19 IC column (solid line). Mobile phase:

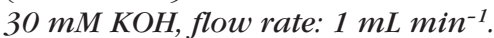

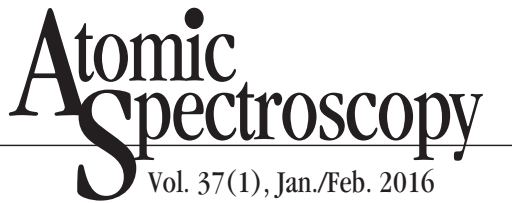

instead of the normal value of 0.92 $\mathrm{mL} \mathrm{min}^{-1}$ ) was used to compensate the plasma cooling effect of carbon addition. Signal intensities of $\mathrm{I}^{+}$as a function of the $\mathrm{CH}_{4}$ gas flow rate, after blank corrections, are illustrated in Figure 3a. The results show that the maximum sensitivity for $\mathrm{I}^{+}$with $3 \mathrm{~mL} \mathrm{~min}^{-1} \mathrm{CH}_{4}$ was five times greater than without addition of $\mathrm{CH}_{4}$. Figure $3 \mathrm{~b}$ compares the results for the iodine species with (solid line) or without (dashed line) addition of $\mathrm{CH}^{4}$ for the IC-ICP-MS method. As shown in Figure 3b, peak heights and peak areas were improved five-fold in the $\mathrm{CH}_{4}$-Ar mixed plasma method over that of the pure Ar plasma method, consistent with both retention times and peak profiles. Compared to the addition of a carbon source (i.e., methanol) to the IC mobile phase, the proposed method $\left(\mathrm{CH}_{4}-\mathrm{Ar}\right.$ mixed plasma) can avoid affecting the separation procedure. The phenomenon of signal enhancement can be explained by a charge transfer reaction occurring between the positively charged carbon species and the high ionization potential $(10.08 \mathrm{eV})$ in the central channel of the plasma $(33,34)$.

\section{Analysis Performance of the Method}

Coexistent substances (i.e., chloride and sulfate) would compete with target ions for sites on the column, thereby causing the peak to elute faster and peak broadening (35). Figure 4 shows the effect of matrices containing 500 $\mathrm{mg} \mathrm{L} \mathrm{L}^{-1}$ chloride $\left(\mathrm{Cl}^{-1}\right)$ and $300 \mathrm{mg}$ $\mathrm{L}^{-1}$ sulfate $\left(\mathrm{SO}_{4}{ }^{2-}\right)$ on the peak profiles of $\mathrm{IO}_{3}{ }^{-}$and $\mathrm{I}^{-}$, respectively. Although the retention times shifted by less than $4 \%$, the peak height and peak area of the matrixcontaining standards were consistent with that of the matrix-free standards. These results indicate that trace level I species can be determined in matrices of anions where concentrations of other ions 


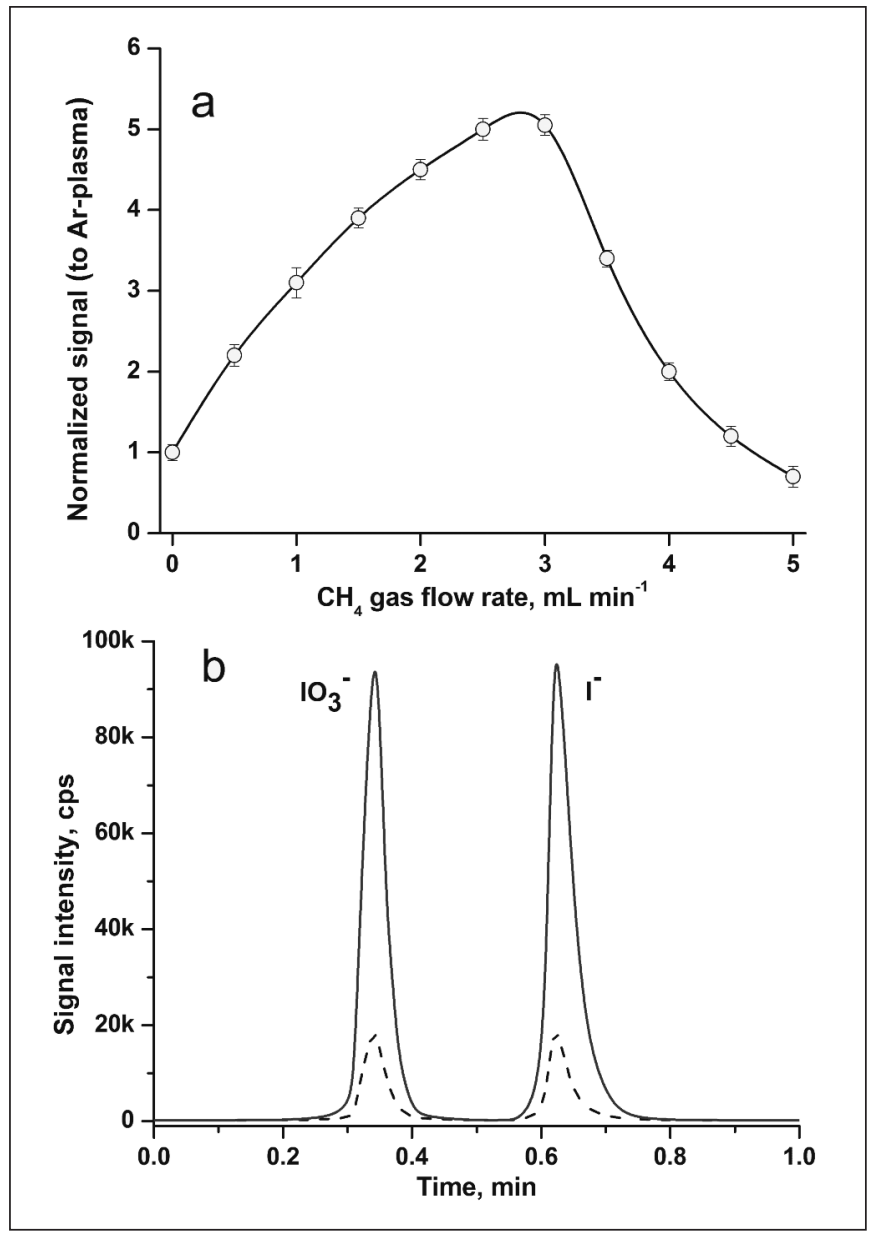

Fig. 3. Effects of $\mathrm{CH}_{4}$ gas flow rate on the normalized signal (to pure Ar plasma) of total iodine (a) and chromatographic peak profiles of the iodine species (b). The dotted line represents not using $\mathrm{CH}_{4}$ gas, the straight line indicates with addi-

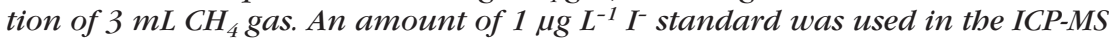
test, and a mixture of $1 \mu \mathrm{g} \mathrm{L}^{-1} \mathrm{IO}_{3}^{-}$and $\mathrm{I}^{-}$standards was used in the IC-ICP-MS analysis.

are 5-6 orders of magnitude higher than that of iodine.

Calibration curves based on peak areas were linear (with correlation coefficients of 0.998 ) for $\mathrm{IO}_{3}{ }^{-}$and $\mathrm{I}^{-}$ in the range tested $\left(0.1-500 \mu \mathrm{g} \mathrm{L}^{-1}\right)$. The limit of detection (LOD) is defined as the concentration which gives peak heights of 3 times the amplitude of the baseline noise. As listed in Table II, the LODs were 0.005 and $0.006 \mu \mathrm{g} \mathrm{L} \mathrm{L}^{-1}$ for $\mathrm{IO}_{3}^{-}$and $\mathrm{I}^{-}$, respectively. Compared to prior literature $(26,27)$, the LOD was around 3-8 times lower, with the total run time per sample reduced

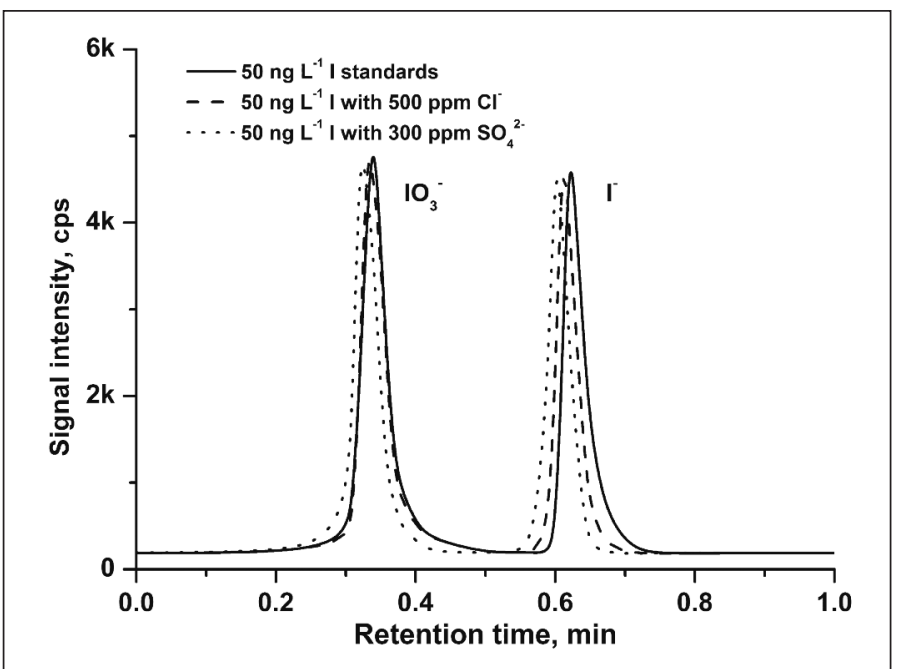

Fig. 4. Effects of matrices containing $500 \mathrm{mg} \mathrm{L}^{-1}$ chloride (dashed line) and $300 \mathrm{mg} \mathrm{L}^{-1}$ sulfate (dotted line) on the peak profiles of $\mathrm{IO}_{3}{ }^{-}$and $\mathrm{I}^{-} .1 \mu \mathrm{g} \mathrm{L}^{-1}$ mixture of $\mathrm{IO}_{3}{ }^{-}$and $\mathrm{I}^{-}$standards was used to test.

\section{Groundwater Sample Analysis}

The proposed method was applied to the determination of I species in seven groundwater samples. Sampling extended from the mountain front plains (Datong basin edge) to the flat alluvial plain regions (central Datong basin). As shown in Table IV, the concentrations of $\mathrm{IO}_{3}{ }^{-}$and $\mathrm{I}^{-}$were in the range of $17.3-49.0 \mu \mathrm{g} \mathrm{L}^{-1}$ and $0.28-1010 \mu \mathrm{g} \mathrm{L}^{-1}$, respectively. Overall, the inorganic I species $\left(\mathrm{IO}_{3}{ }^{-}\right.$plus $\left.\mathrm{I}^{-}\right)$in the three samples from the mountain front plains were significantly lower than in the four samples from the flat alluvial plain regions. $\mathrm{IO}_{3}{ }^{-}$was the main species at the basin edge, while $\mathrm{I}^{-}$ was the main species in the central basin (Figure 6). Different distributions of I species at the edge and center of the basin suggested that the mobilization process of iodine was associated with complex redox conditions (36). A comparison of inorganic I species $\left(\mathrm{IO}_{3}{ }^{-}\right.$and $\left.\mathrm{I}^{-}\right)$ with the total iodine concentrations indicated the presence of some unknown iodine species (i.e., organic I compounds) in these groundwater samples. A more in- 
TABLE II

Analytical Figures of Merit for Different HPLC-ICP-MS Methods

\begin{tabular}{lccccc}
\hline $\begin{array}{l}\text { Analytical } \\
\text { Method }\end{array}$ & $\begin{array}{c}\text { Detection Limit } \\
\left(\mu \mathrm{g} \mathrm{L}^{-1}\right)\end{array}$ & \multicolumn{2}{c}{$\begin{array}{c}\text { Retention Time } \\
(\mathrm{min})\end{array}$} & $\begin{array}{c}\text { Total Run Time } \\
(\mathrm{min})\end{array}$ \\
\hline $\mathrm{IC}^{-} \mathrm{ICP}-\mathrm{MS}^{\mathrm{a}}$ & 0.050 & 0.040 & 4.4 & 9.5 & 12 \\
SEC-ICP-MS $^{\mathrm{b}}$ & 0.025 & 0.025 & 9.7 & 15.4 & 16 \\
This work $^{\mathrm{c}}$ & 0.005 & 0.006 & 0.36 & 0.64 & 1 \\
\hline
\end{tabular}

${ }^{a}$ Separation with Dionex AS16 ion exchange column (26).

${ }^{b}$ Separation with TSK G3000PWSEC column (27).

c Separation with Dionex AG-19 ion exchange column and analysis by the mixed Ar- $\mathrm{CH}_{4}$ plasma ICP-MS.

TABLE III

Results of $\mathrm{IO}_{3}^{-}$and $\mathrm{I}^{-}$in Three Standard Reference Materials (SRMs) by the Proposed Method $\left(\mu \mathrm{g} \mathrm{L} \mathrm{L}^{-1}, \mathrm{n}=3\right)$

\begin{tabular}{|c|c|c|c|c|}
\hline \multirow[t]{2}{*}{ SRMs } & \multicolumn{2}{|c|}{$\mathrm{IO}_{3}^{-}$} & \multicolumn{2}{|c|}{$\mathrm{I}^{-}$} \\
\hline & $\begin{array}{c}\text { Detected } \\
\text { Values }\end{array}$ & $\begin{array}{c}\text { Certified } \\
\text { Values }\end{array}$ & $\begin{array}{l}\text { Detected } \\
\text { Values }\end{array}$ & $\begin{array}{c}\text { Certified } \\
\text { Values }\end{array}$ \\
\hline BCR-611 & & & & \\
\hline Groundwater & $0.11 \pm 0.01$ & $-c$ & $9.2 \pm 0.2$ & $9.0 \pm 1.1$ \\
\hline $\begin{array}{l}\text { GBW08621 } \\
\text { Natural Water }\end{array}$ & $2.13 \pm 0.04$ & 2.14 & N.D. ${ }^{b}$ & $-{ }^{c}$ \\
\hline $\begin{array}{l}\text { GBW(E)080235 } \\
\text { Natural Water }\end{array}$ & N.D. ${ }^{b}$ & $--^{c}$ & $202 \pm 4$ & $200 \pm 10$ \\
\hline
\end{tabular}

${ }^{a}$ Actual samples diluted 100,000-fold.

${ }^{b}$ Not detected.

${ }^{\mathrm{c}}$ Not available.

\section{Atomic Apectroscopy \\ Vol. 37(1), Jan./Feb. 2016}

depth study by examining the fragmentation pattern with organic mass spectrometry (LC-MS-MS) would be required to identify the organic I species present.

\section{CONCLUSION}

The combination of a short anion-exchange column (Dionex AG-19) IC system with $\mathrm{CH}_{4}-\mathrm{Ar}$ mixed plasma ICP-MS was used to determine amounts of iodate and iodide in groundwater samples. The total separation time per sample reduced from 12-16 minutes to 1 minute, and the analytical sensitivity of iodine was improved fivefold. The detection limit was 0.005 $\mu \mathrm{g} \mathrm{L}^{-1}$ for $\mathrm{IO}_{3}{ }^{-}$and $0.006 \mu \mathrm{g} \mathrm{L} \mathrm{L}^{-1}$ for $\mathrm{I}^{-}$, while the relative standard deviation for five injections of $0.2 \mu \mathrm{g} \mathrm{L}^{-1}$ $\mathrm{I}^{-}$or $\mathrm{IO}_{3}{ }^{-}$was $1.2-3.3 \%$. The adopted system for separation and detection provides an excellent, rapid, and sensitive technique for iodine speciation.

\section{ACKNOWLEDGMENTS}

This work was supported by the National Nature Science Foundation of China (No. 21175120 and 21207120) and the National Key

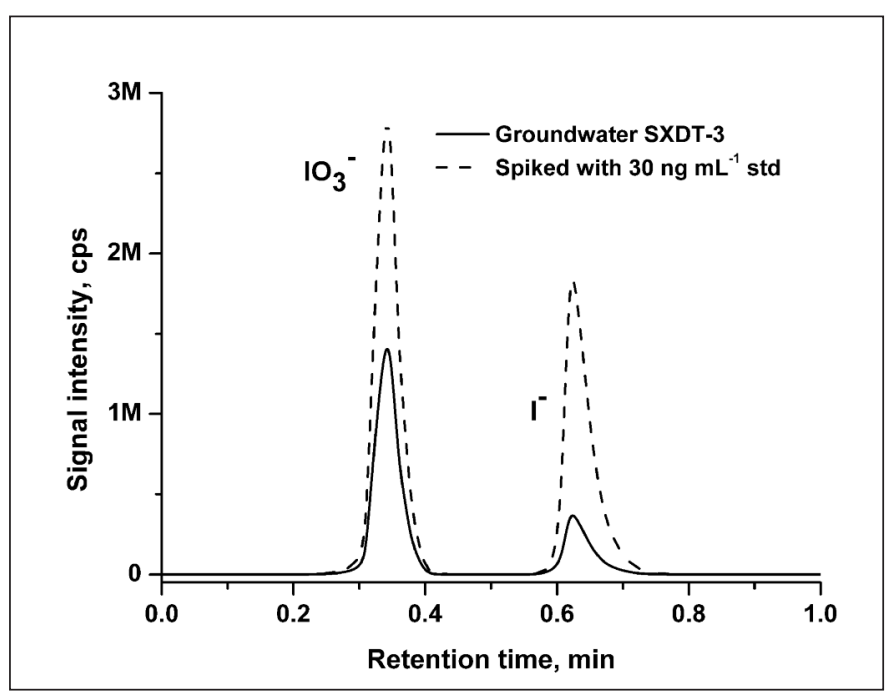

Fig. 5. Groundwater chromatograms for the recovery test using a groundwater sample (SXDT-3) collected from mountain front plains of the Datong basin.

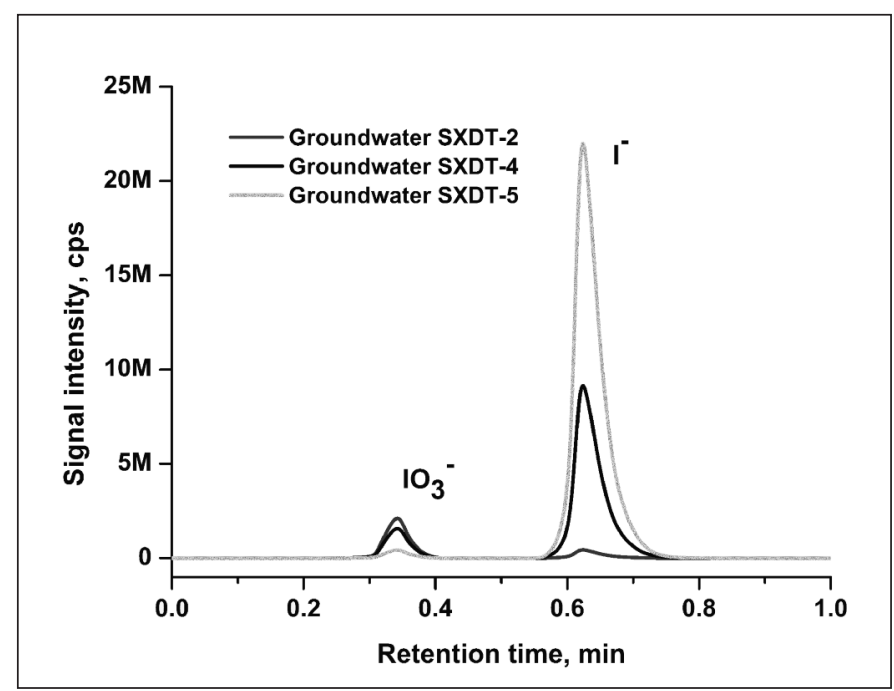

Fig. 6. Typical groundwater chromatograms for samples collected at different regions of the Datong basin. 
TABLE IV

Results of $\mathrm{IO}_{3}{ }^{-}$and $\mathrm{I}^{-}$in 7 Groundwater Samples by the Proposed Method ( $\mu \mathrm{L} \mathrm{L}^{-1}, \mathrm{n}=3$ )

\begin{tabular}{clcccc}
\hline Sample & \multicolumn{1}{c}{ Area } & \multicolumn{3}{c}{ Inorganic Iodine } & $\mathrm{IO}_{3}^{-}$ \\
& & $17.3 \pm 0.4$ & $0.280 \pm 0.022$ & 17.6 & $\mathrm{I}^{-}$ \\
\hline SXDT-1 & Mountain front plains & $45.2 \pm 0.6$ & $9.26 \pm 0.18$ & 54.5 & $18.2 \pm 0.3$ \\
SXDT-2 & Mountain front plains & $30.2 \pm 0.5$ & $7.73 \pm 0.25$ & 37.9 & $59.0 \pm 1.0$ \\
SXDT-3 & Mountain front plains & $33.6 \pm 0.5$ & $192 \pm 5$ & 226 & $43.0 \pm 1.1$ \\
SXDT-4 & Flat alluvial plain regions & $9.20 \pm 0.5$ & $462 \pm 11$ & 471 & $296 \pm 4$ \\
SXDT-5 & Flat alluvial plain regions & $4.54 \pm 0.4$ & $888 \pm 26$ & 893 & $471 \pm 10$ \\
SXDT-6 & Flat alluvial plain regions & $49.0 \pm 1.2$ & $1,010 \pm 32$ & 1059 & $1041 \pm 17$ \\
SXDT-7 & Flat alluvial plain regions & & & & $1079 \pm 21$ \\
\hline
\end{tabular}

${ }^{\text {a }}$ Direct analysis by ICP-MS without IC separation.

Scientific Instrument and Equipment Development Projects of China (No. 2011YQ06010008), and the Fundamental Research Funds for the Central Universities, China University of Geosciences (Wuhan) (No. CUGL140411).

Received July 23, 2015.

\section{REFERENCES}

1. A. Moreda-Pineiro, V. RomarisHortas, and P. Bermejo-Barrera, J. Anal. At. Spectrom. 26, 2107 (2011).

2. G.R. Delong, Science 336, 1504 (2012).

3. J.X. Li, Y.X. Wang, X.J. Xie, L.P. Zhang, and W. Guo, Environ. SciProc. Imp. 15, 848 (2013).

4. K.E. Wang and S.J. Jiang, Anal. Sci. 24, 509 (2008).

5. X.Z. Cheng, Y. Peng, K. Cheng, Y.Y. Song, and S.X. Zhang, At. Spectrosc. 34, 199 (2013).

6. S. Ghanthimathi, N.B. Ibrahim, Z.B. Nasir, L. Lim, and K. Ong, At. Spectrosc. 32, 85 (2011).

7 T. Eickhorst and A. Seubert, J. Chromatogr. A 1050, 103 (2004).

8. W. Liu, H.X. Yang, B. Li, and S.Q. $\mathrm{Xu}$, Geostand. Geoanal. Res. 35, 69 (2011).

9. M. Shah, R.G. Wuilloud, S.S. Kannamkumaratha, J.A. Caruso, J. Anal. At. Spectrom., 20, 176 (2005).
10. Y.S. Shimamoto and Y. Takahashi, Geochim. Cosmochim. Acta72, A860 (2008).

11. J. Zheng, M. Yamada, and S. Yoshida, J. Anal. At. Spectrom. 26, 1790 (2011).

12. V. Padmasubashini and K. Satyanarayana, At. Spectrosc. 34, 6 (2013).

13. M.A. Reddy, R. Shekhar, and S.J. Kumar, At. Spectrosc. 34, 119 (2013).

14. Y.Z. Yi, S.Y. Wu, S.J. Jiang, and A.C. Sahayam, At. Spectrosc. 34, 39 (2013).

15. S.Z. Chen, S.P. Zhu, and D.B. Lu, At. Spectrosc. 35, 103 (2014).

16. S.Z. Chen, S.P. Zhu, and D.B. Lu, At. Spectrosc. 35, 1 (2014).

17. X.L. Guo, S.Z. Chen, Y. Zhang, and D.B. Lu, At. Spectrosc. 35, 55 (2014).

18. B.K. Nagar, A. Saha, S.B. Deb, and M.K. Saxena,At. Spectrosc. 35, 187 (2014).

19. J.Y. Zhang, G.M. Li, and W. Guo, At. Spectrosc. 35, 97 (2014).

20. Y. Zhang, S.Z. Chen, X.L. Guo, and D.B. Lu, At. Spectrosc. 35, 235 (2014).

21. J.D. Ruiz-Diaz, M. Savio, M.F. Moyano, E.E. Verni, L.D. Martinez, and R.A. Gil, At. Spectrosc. 36, 55 (2015).

22. B. Michalke, H. Witte, J. Trace Elem. Med. Bio. 29, 63 (2015).

23. X. Han, L.H. Cao, H.Y. Cheng, J.H. Liu, and Z.G. Xu, Anal. Methods 4 , 3471 (2012).
24. Z. Nie, L.N. Zheng, W.Y. Feng, and C.L. Liu, Anal. Methods 6, 8380 (2014)

25. C. Han, J.N. Sun, H.Y. Cheng, J.H. Liu, and Z.G. Xu, Anal. Methods 6, 5369(2014).

26. B.S. Gilfedder, M. Petri, and H. Biester, Atmos. Chem. Phys. 7, 2661 (2007).

27. H.X. Yang, W. Liu, B. Li, H..J. Zhang, X.D. Liu, and D.Y. Chen, Geostand. Geoanal. Res. 31, 345 (2007).

28. Z.L. Chen, M. Megharaj, and R. Naidu, Chromatographia 65, 115 (2007).

29. P. Allain, L. Jaunault, Y. Mauras, J.M. Mermet, and T. Delaporte, Anal. Chem. 63, 1497 (1991).

30. W. Guo, S.H. Hu, X.F. Li, J. Zhao, S.S. Jin, W.J. Liu, and H.F. Zhang, Talanta84, 887 (2011).

31. W. Guo, S.H. Hu, Y.X. Wang, L.Y. Zhang, Z.C. Hu, and J.Y. Zhang, Microchem. J. 108, 106 (2013).

32. W. Guo, S.H. Hu, J.Y. Zhang, L.L. Jin, X.J. Wang, Z.L. Zhu, and H.F. Zhang, J. Anal. At. Spectrom. 26 , 2076 (2011)

33. Z.C. Hu, S.H. Hu, S. Gao, Y.S. Liu, and S.L. Lin, Spectrochim. Acta B59, 1463 (2004).

34. A.S. Al-Ammar, E. Reitznerova, and R.M. Barnes, Spectrochim. Acta B54, 1813 (1999).

35. B.H. Zhu, Z.X. Zhong, and J. Yao, J. Chromatogr. A1118, 106 (2006).

36. J.X. Li, Y.X. Wang, W. Guo, X.J. S.Q. Kong, Sci. Total. Environ. 468, 738 (2014). 